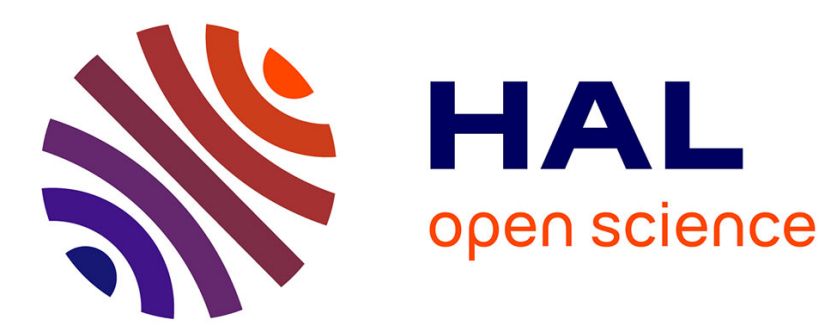

\title{
THE EFFECT OF FRICTION ON SIMULATED DYNAMIC FRACTURING OF ROCKS
}

\author{
A. Attia
}

\section{To cite this version:}

A. Attia. THE EFFECT OF FRICTION ON SIMULATED DYNAMIC FRACTURING OF ROCKS. Journal de Physique IV Proceedings, 1991, 01 (C3), pp.C3-745-C3-750. 10.1051/jp4:19913105 . jpa00249907

\section{HAL Id: jpa-00249907 https://hal.science/jpa-00249907}

Submitted on 1 Jan 1991

HAL is a multi-disciplinary open access archive for the deposit and dissemination of scientific research documents, whether they are published or not. The documents may come from teaching and research institutions in France or abroad, or from public or private research centers.
L'archive ouverte pluridisciplinaire HAL, est destinée au dépôt et à la diffusion de documents scientifiques de niveau recherche, publiés ou non, émanant des établissements d'enseignement et de recherche français ou étrangers, des laboratoires publics ou privés. 
Colloque C3, suppl. au Journal de Physique III, Vol. 1, octobre 1991

THE EFFECT OF FRICTION ON SIMULATED DYNAMIC FRACTURING OF ROCKS

\author{
A.V. ATTIA \\ Lawrence Livermore National Laboratory, P.O. Box 808, L-200, \\ Livermore, California 94551-0808, U.S.A.
}

\begin{abstract}
During underground nuclear tests, rocks may fail by plastic yielding, which limits shear strength, or by tensile fracture, wherever maximum principal stress exceeds tensile strength. A third mode of failure exists due to friction along closed fractured surfaces. There, friction affects slipping and can thus limit stress. In this paper, we study the effect of friction on the simulated dynamic response of rocks to underground nuclear explosions. The coefficient of friction is the ratio of total shear stress applied to a closed fracture surface to normal applied compressive total stress. At low coefficients of friction, the evolving stress field tends to be weakened by frictional slip, which also eases closing of fractures. At high coefficients of friction, the stress field tends to be strengthened, where fractures have closed, but remains weak, where fractures are left open.
\end{abstract}

\title{
INTRODUCTION
}

The goal of this work is to evaluate the role of friction along closed rock fractures on simulated containment of underground nuclear explosions. An earlier report ${ }^{1}$ provides a complete description of the theoretical formulation and numerical implementation of the material model. This analysis will focus on the Paleozoic layer, just below the cavity, because the effect of friction is most prominent in this region, which shows considerable cracking.

After summarizing the material model, the effect of friction on the rock response is discussed, for the simulation, which was performed using the KDYNA code. ${ }^{2}$

\section{MATERIAL MODEL}

\section{Constitutive Model}

In order to satisfy constraints of tensile fracture and plasticity, Rubin ${ }^{1}$ decomposes the total stress $\mathrm{T}$ :

$$
\underline{T}=\underline{T}_{u}+\underline{T}_{v}
$$

where $\underline{T}_{u}$ is the stress in the unfractured material, and $\underline{T}_{v}$ is a void stress in response to the fractures in the material. A linear relation is assumed between void stress and void strain, $\underline{e}_{v}$, which is a continuum tensor measure of crack opening:

$$
\underline{\mathrm{T}}_{\mathrm{v}}=-\lambda_{0}\left(\operatorname{tr} \underline{\mathrm{e}}_{\mathrm{v}}\right) \underline{I}-2 \mathrm{G}_{0} \underline{\mathrm{e}}_{\mathrm{v}}
$$

where $\lambda_{0}$ is Lame's constant, and $G_{0}$ is the shear modulus. The total pressure is then: 


$$
\mathrm{p}=\hat{\mathrm{p}}\left(\mu, \mu_{\max }\right)-\frac{1}{3}\left(\operatorname{tr} \underline{\mathrm{T}}_{\mathrm{v}}\right)
$$

where $\hat{p}\left(\mu, \mu_{\text {max }}\right)$ is the pressure in the porous unfractured material, in response to both the current and peak values of excess compression:

$$
\mu=\rho / \rho_{0}-1
$$

where $\rho$ is the mass density in the present configuration, $\rho_{0}$ is its reference value.

Deviatoric unfractured stress $T_{\mathfrak{u}}$ is determined from a hypoelastic equation:

$$
\underline{\nabla}_{u}^{\prime}=2 G\left(\underline{D}^{\prime}-\underline{D}_{\mathrm{p}}\right)
$$

where $\stackrel{\nabla}{T}_{u}^{\prime}$ is the Jaumann stress rate and the rate of plastic deformation $\underline{D}_{p}$ is determined by the flow rule:

$$
\underline{\mathrm{D}}_{\mathrm{p}}=\Gamma \underline{\mathrm{T}}_{\mathrm{u}}^{\prime}
$$

where $\Gamma$ is determined so that the unfractured deviatoric stress does not exceed a yield strength limit $Y$, according to Rubin's yield model $^{3}$ :

$$
\sigma_{e}^{2}=\frac{3}{2} \operatorname{tr}\left(\underline{T}_{u}^{\prime} \cdot \underline{T}_{u}^{\prime}\right) \leq Y
$$

\section{Fracture Frame and Cracking}

In order to follow the direction of crack opening, an orthonormal fracture triad $\left\{\underline{n}_{1}, \underline{n}_{2}, \underline{n}_{3}\right\}$ is introduced. Before fracturing, this triad coincides with the principal directions of stress. Fracture is initiated when the maximum principal stress equals the tensile strength. Once a fracture has formed, diagonal components of the void strain (relative to the fracture triad) are determined such that the normal component of total stress vanishes, when the fracture is open, but remains compressive, when the fracture is closed. Up to three orthogonal fractures are allowed. Complete solution details for one, two, and three fractures are given in Reference 1.

\section{Friction Mode1}

Off-Diagonal components of void strain (relative to the fracture triad) are determined such that the magnitude of the total shear, $\tau^{*}$, applied to each closed fracture surface never exceeds a friction coefficient, $\mu_{\mathrm{f}}$, times the normal applied compressive total stress on the closed crack. The complete friction model allows for up to three fractures. Here we consider a single closed fracture in the R-Z plane, in axisymmetric geometry.

The trial shear stress is

$$
\mathrm{T}_{12}^{*}=\mathrm{T}_{\mathrm{u} 12}-2 \mathrm{G}_{0} \mathrm{e}_{\mathrm{v} 12}^{\mathrm{old}}
$$

Since $\mathrm{T}_{13}=0$ in axisymmetry, the total applied shear stress is given by:

$$
\tau^{*}=\sqrt{\left(\mathrm{T}_{12}^{*}\right)^{2}+\left(\mathrm{T}_{13}^{*}\right)^{2}}=\left|\mathrm{T}_{12}^{*}\right|
$$


If $\tau^{*}>\mu_{\mathrm{f}}\left(-\mathrm{T}_{11}\right)$ then there is slip measured by the slip fraction $\beta_{\mathrm{f}}$ :

$$
\beta_{\mathrm{f}}=1-\frac{\mu_{\mathrm{f}}\left(-\mathrm{T}_{11}\right)}{\tau^{*}}
$$

If $\tau^{*} \leq \mu_{\mathrm{f}}\left(-\mathrm{T}_{11}\right)$ then there is no slip; i.e. $\beta_{\mathrm{f}}=0$. The final shear stress is limited by slipping:

$$
\mathrm{T}_{12}=\left(1-\beta_{\mathrm{f}}\right) \ddot{\mathrm{T}}_{12}^{*}
$$

The new off-diagonal component of void strain becomes:

$$
\mathrm{e}_{\mathrm{v12}}^{\mathrm{new}}=\left(1-\beta_{\mathrm{f}}\right) \mathrm{e}_{\mathrm{v12}}^{\text {old }}+\beta_{\mathrm{f}}\left(\frac{\mathrm{T}_{\mathrm{u} 12}}{2 \mathrm{G}_{0}}\right)
$$

\section{EFFECT OF FRICTION ON ROCK RESPONSE}

$\underline{\text { Results }}$

Figure 1 shows the geological layering. For a detailed description of the material properties and boundary conditions, see Reference 4.

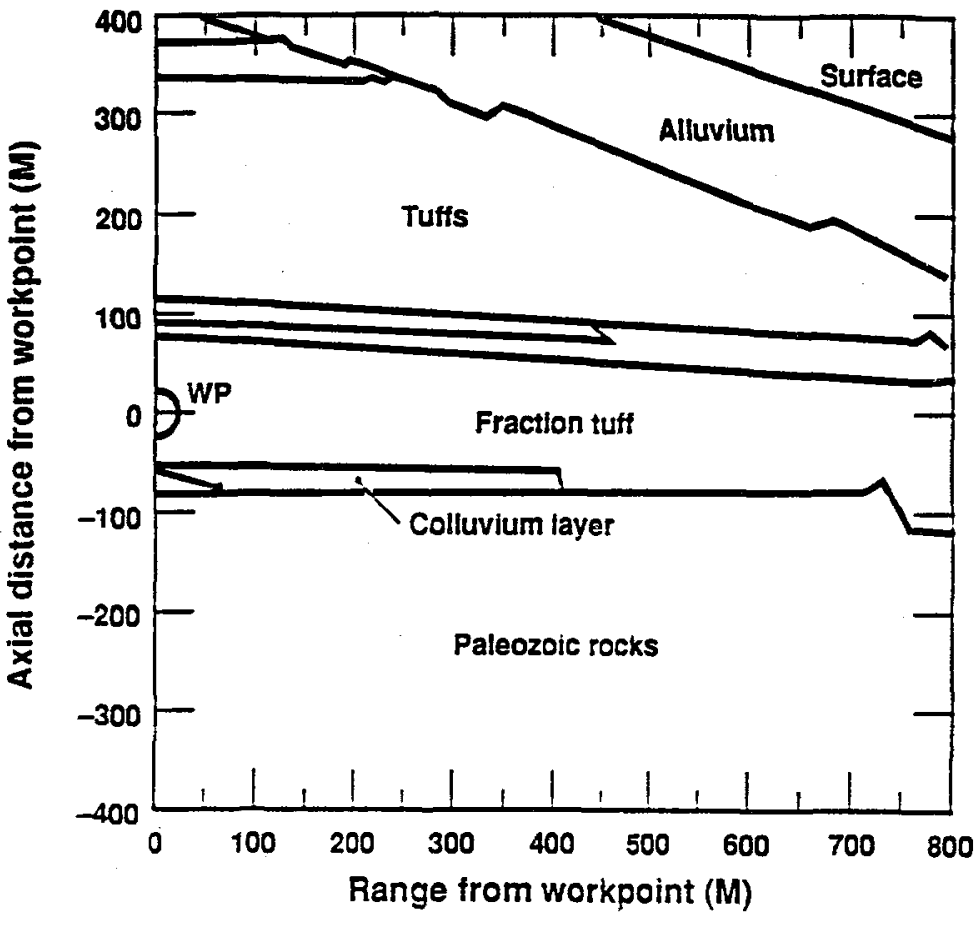

Figure 1. Geological Layering.
Figures 2, 3, and 4 show the effect of friction on the rock response, in the Paleozoic layer, at $0.5 \mathrm{sec}-$ ond, when the response has reached a sufficiently steady state to be considered as residual. Figure 2 shows the considerable reduction in $\operatorname{slip}\left(\beta_{\mathrm{f}}\right)$, when $\mu_{\mathrm{f}}$ increases from 0 to 0.5 . Further increase in $\mu_{\mathrm{f}}$ from 0.5 to 0.8 causes only a minor change in slip (this is not shown here). Figure 3 shows $\operatorname{tr}\left(\underline{\mathrm{e}}_{\mathrm{v}}\right)$, the volumetric void strain. Notice that with no friction $\left(\mu_{\mathrm{f}}=0\right)$, most cracks are closed. As $\mu_{\mathrm{f}}$ increases to 0.5 and 0.8 , we

see that the cracked rock region becomes steadily more extensive, and that residual voids increase in magnitude.

Figure 4 shows the effect of friction on the residual out-of-plane hoop stress, shown positive in compression. Notice that with no friction (Figure $4(\mathrm{a})$ ), the stress field is weakest. When $\mu_{\mathrm{f}}$ is increased to 0.5 , the stress field reaches stronger compressive values over a larger region of the Paleozoic layer. When $\mu_{f}$ is 
further increased to 0.8 , the stress field remains strong only where cracks are closed (as seen from Figure $3(\mathrm{c})$ ). However, the stress field remains weak where more cracks have appeared in increasing $\mu_{\mathrm{f}}$ from 0.5 to 0.8 (Figures $3(b, c)$ ).

\section{Effect of Layering}

The extensive cracking in the Paleozoic layer allows the effect of friction to be observed. This cracking may be explained by considering the contrast in material properties ${ }^{4}$ between the Paleozoic layer and the adjoining upper colluvium layer. These material properties show that the impedance ratio between the Paleozoic and Colluvium layers is 3.64 , while the impedance ratios across other layers are very close to unity. Since the impedance ratio at the Paleozoic/Colluvium interface is much greater than at other interfaces, at upper layers, it is not surprising that the explosion's blast wave has such a shattering effect on the Paleozoic layer. We can see that a compressive pulse emanating from the explosion is first strongly reflected from the Paleozoic layer back to the cavity. There, the compressive pulse will be reflected as an intense rarefaction. To understand the effect of the rarefaction, we now consider the yield strength of the various layers. Reference 4 shows that the Paintbrush Tuff and Paleozoic layers have greater yield strengths than the Colluvium layers or the Fraction Tuff layer. Thus, the unfractured deviatoric stress will be limited more severely in the Colluvium layer than in the Paleozoic layer. Consequently, when a rarefaction penetrates the Colluvium layer, tensile unfractured deviatoric stress will be limited as the material yields (Eq. 7), preventing tensile failure. However, a rarefaction in the Paleozoic layer can cause a tensile unfractured stress without the same low Colluvium layer yield limit, thus allowing tensile failure.

\section{CONCLUSIONS}

In this simulation, we have examined the role of friction in the dynamic fracture of a high-impedance rock layer, when a nuclear explosion is embedded in a nearby low-impedance layer. Friction allows observing a new mode of failure, by limiting shear void stress on closed cracks, in addition to plastic failure, which limits uncracked deviatoric stress. At low friction coefficients, the residual stress field is weakened by frictional slip, which eases closing of residual cracks. At high friction coefficients, the residual stress field is strengthened, where cracks have remained closed. However, the stress field is forced to remain weak, where cracks have remained open.

\section{ACKNOWLEDGEMENTS}

Work performed under the auspices of the U. S. Department of Energy by the Lawrence Livermore National Laboratory under contract W-7405-ENG-48.

\section{REFERENCES}

1. M. B. Rubin, A. V. Attia, "A Continuum Tensile Failure Model with Friction", Lawrence Livermore National Laboratory Report UCRL-ID-104759, August 1990.

2. J. L. Levatin, A. V. Attia, J. O. Hallquist, KDYNA User's Manual, Lawrence Livermore National Laboratory Report UCRL-ID-106104, September 28, 1990.

3. M. B. Rubin, "A Simple and Convenient Isotropic Failure Surface", Lawrence Livermore National Laboratory Report UCRL-102556, 1989.

4. R. P. Swift, J. T. Rambo, J. B. Bryan, "The Role of Calculations to Define Containment Phenomenology in Complex Geology', Lawrence Livermore National Laboratory Report UCRL92437, September 1985. 
(a) $\mu_{f}=0$

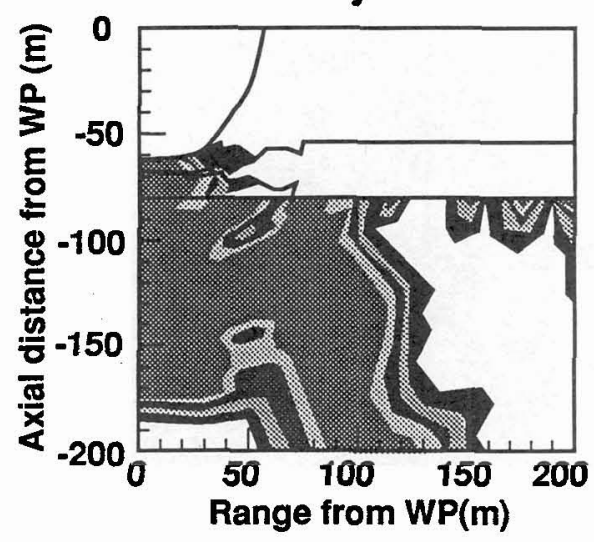

Figure 2: Residual slip fraction

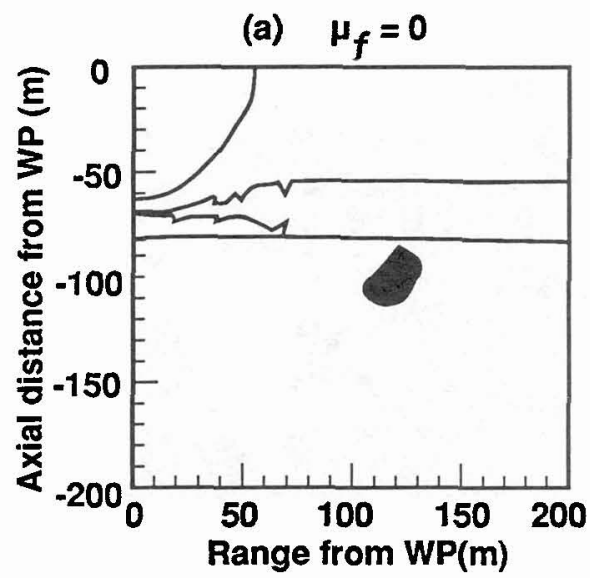

Silp fraction

$0.8=$ (b) $\mu_{f}=0.5$

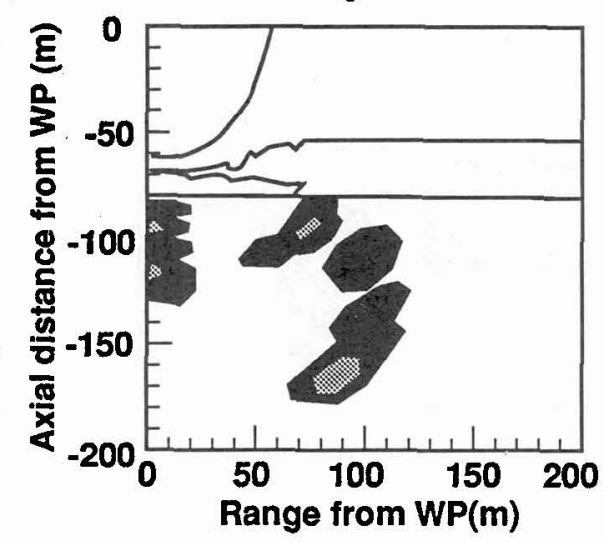

0.0
0.2
0.4
0.6
0.8

Figure 3: Residual volumetric void strain (\%)

\begin{tabular}{c|l|}
\hline & .0001 \\
Void & .0005 \\
strain & .0010 \\
(\%) & $.0050=$ \\
\hline & 0100 \\
\hline
\end{tabular}

(b) $\mu_{f}=0.5$

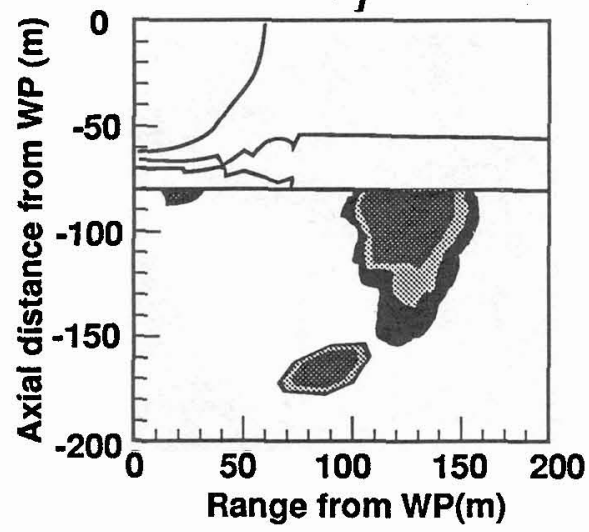




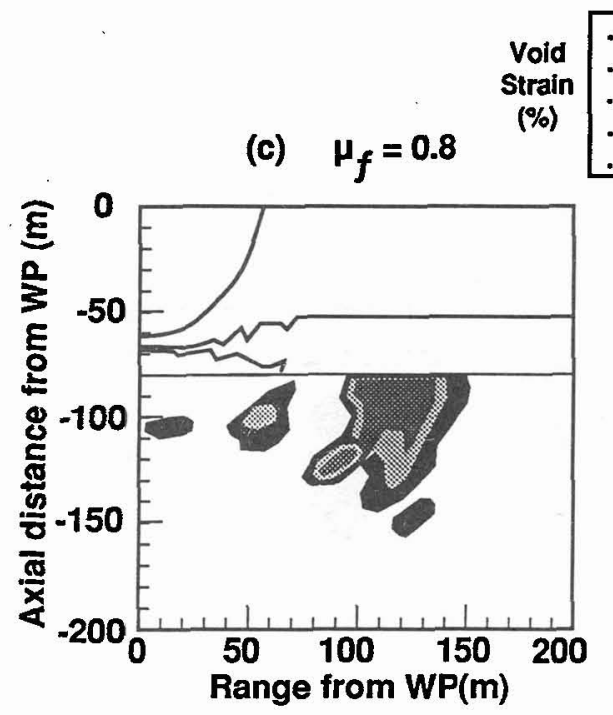

Figure 3: Residual volumetric void strain (\%)

(b) $\quad \mu_{f}=0.5$

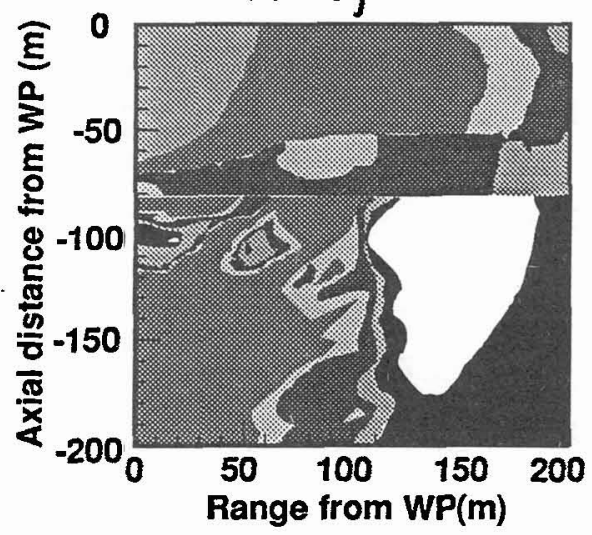

(a) $\mu_{f}=0$

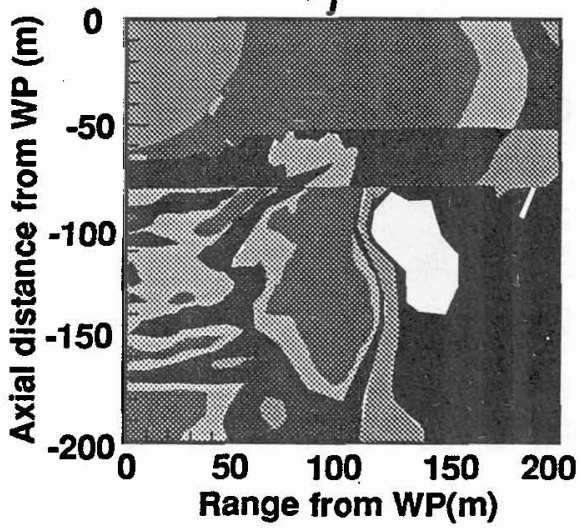

Figure 4: Residual out-of-plane hoop stress (bars)

(c) $\mu_{f}=0.8$

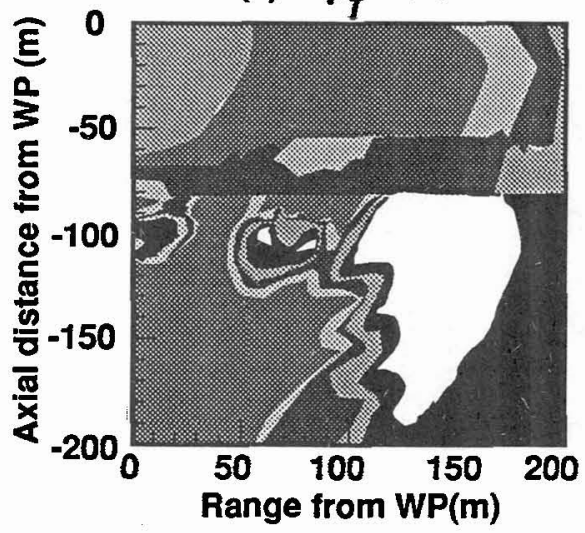

Figure 4: Residual out-of-plane hoop stress (bars)

ES-0418M1-AAMB-01

\begin{tabular}{l|c|}
\hline Stress & 50 \\
100 \\
150 \\
(bars) \\
200 \\
250 \\
\hline
\end{tabular}

